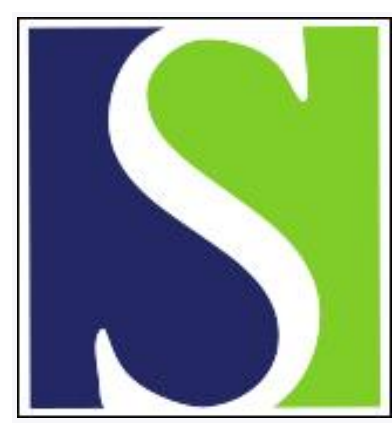

Scand J Work Environ Health 2015;41(1):105-106

https://doi.org/10.5271/sjweh.3451

Published online: 25 Aug 2014, Issue date: 01 Jan 2015

Re: Bracci M et al. "Rotating-shift nurses after a day off: peripheral clock gene expression, urinary melatonin, and serum 17-estradiol levels."

by Stevens RG, Zhu Y

Affiliation: University of Connecticut Health Center, Farmington, CT, 06030-6325, USA. bugs@uchc.edu

Refers to the following text of the Journal: 2014;40(3):295-304

Key terms: 6-sulfatoxymelatonin; breast cancer; chronotype; circadian rhythm; clock gene; night work; nurse; peripheral clock gene expression; rotating shift; serum 17-estradiol; shift; shift work; urinary melatonin

This article in PubMed: www.ncbi.nlm.nih.gov/pubmed/25153335 


\section{Re: Bracci M et al. "Rotating-shift nurses after a day off: peripheral clock gene expression, urinary melatonin, and serum 17-estradiol levels."}

Bracci et al (1) conducted an important study of the expression of nine circadian genes and the levels of melatonin and estradiol among female nurses working a rotating shift schedule compared to nurses on a dayonly shift. Rotating shift is perhaps the most disruptive to circadian physiology and sleep (2). The authors found elevated estradiol levels in the blood of rotating- compared to day-shift nurses, but no significant difference in the urinary melatonin metabolite 6-sulphatoxymelatonin. Their interpretation was that because there was a day off between last work shift and collection of overnight urine specimens, melatonin production in the night workers had rebounded from the last night shift worked, whereas the change in estradiol in blood was a longer lasting effect of chronic shift work and the circadian disruption that it entails. Elevated estradiol from exposure to light at night, via melatonin suppression, was the first mechanism offered for an elevated risk of breast cancer in women in the industrialized world (3).

In addition, Bracci et al (1) found greater levels of expression of certain circadian genes and lower levels of others. A couple of years ago, we published results from a small study of women working the night shift in Denmark compared to day-working women (4). We had hypothesized that expression of $C L O C K$ would be higher and $C R Y 2$ would be lower in the peripheral blood lymphocytes (PBL) of night-working women. Due to the type of samples available to us, we could not examine transcript levels and so rather we looked at the degree of promoter methylation with the inference that hypomethylation was consistent with increased gene expression and hypermethylation consistent with decreased gene expression. Our reasoning was that $C L O C K$ acts a transcriptional activator within the circadian molecular machinery, whereas $C R Y 2$ acts as a transcriptional repressor; therefore CLOCK may be more generally an "oncogene" and CRY2 a "tumor suppressor". We had previously found that women with breast cancer showed hypomethylation of CLOCK (5) and hypermethylation of $C R Y 2$ (6) compared to population controls, consistent with our prediction. Since shiftworking women have been reported to be at increased risk of breast cancer (7), we reasoned that shift workers in general would show these same changes systemically in CLOCK and CRY2 expression.

Using a more direct approach, Bracci et al (1) also found evidence for elevated CLOCK gene expression in
PBL of night-working women compared to day workers, and lower expression of CRY2. Although each of the nine or so core circadian genes has a specific function within the circadian feedback loop, it is becoming clear that each also has many other functions in physiology systemically (eg, 8); as much as $10 \%$ of the entire genome is under direct circadian control (9). The other gene expression changes Bracci et al (1) found undoubtedly have implications far beyond the cellular clock itself.

If the gene expression changes found by Bracci et al (1) and the DNA methylation changes we observed (4) are replicable, then they are quite important. These consistent changes should be examined in women and men working less disruptive non-day shifts such as permanent evening or night. In addition, even among day working people, greater exposure to light at night might also yield changes in gene expression pertinent to cancer risk. With these expression markers of circadian disruption, there may ultimately result a better understanding of the links among electric lighting, circadian disruption, and breast cancer and other diseases. The long-term goal is, of course, better use of lighting for work, play, and health (10).

\section{References}

1. Bracci M, Manzella N, Copertaro A, Staffolani S, Strafella E, Barbaresi M, et al. Rotating-shift nurses after a day off: peripheral clock gene expression, urinary melatonin, and serum 17- $\beta$-estradiol levels. Scand J Work Environ Health. 2014;40:295-304. http://dx.doi.org/10.5271/sjweh.3414.

2. Stevens RG, Hansen J, Costa G, Haus E, Kauppinen T, Aronson KJ, et al. Considerations of circadian impact for defining 'shift work' in cancer studies: IARC Working Group Report. Occup Environ Med. 2011;68:154-62. http://dx.doi. org/10.1136/oem.2009.053512.

3. Stevens, RG: Review and Commentary: Electric power use and breast cancer: a hypothesis. Am J Epidemiol, 1987;125:556-561.

4. Zhu Y, Stevens RG, Hoffman AE, Tjonneland A, Vogel UB, Zheng T, Hansen J. Epigenetic impact of long-term shiftwork: pilot evidence from circadian genes and whole-genome methylation analysis. Chronobiol Int. 2011;28:852-61. http:// dx.doi.org/10.3109/07420528.2011.618896. 
5. Hoffman AE, Yi CH, Zheng T, Stevens RG, Leaderer D, Zhang Y, et al. CLOCK in breast tumorigenesis: genetic, epigenetic, and transcriptional profiling analyses. Cancer Res. 2010;70:1459-68. http://dx.doi.org/10.1158/0008-5472. CAN-09-3798.

6. Hoffman AE, Zheng T, Yi CH, Stevens RG, Ba Y, Zhang Y, et al. The core circadian gene Cryptochrome 2 influences breast cancer risk, possibly by mediating hormone signaling. Cancer Prev Res (Phila). 2010;3:539-48. http://dx.doi. org/10.1158/1940-6207.CAPR-09-0127.

7. Straif K, Baan R, Grosse Y, Secretan B, El Ghissassi F, Bouvard V, et al. Carcinogenicity of shift-work, painting, and fire-fighting. Lancet Oncol 2007;8:1065-6. http://dx.doi. org/10.1016/S1470-2045(07)70373-X.

8. Masri S, Cervantes M, Sassone-Corsi P. The circadian clock and cell cycle: interconnected biological circuits. Curr Opin Cell Biol. 2013;25:730-4. http://dx.doi.org/10.1016/j. ceb.2013.07.013.

9. Takahashi JS, Hong HK, Ko CH, McDearmon EL. The genetics of mammalian circadian order and disorder: implications for physiology and disease. Nat Rev Genet 2008;9:764-75. http:// dx.doi.org/10.1038/nrg2430.

10. Stevens RG, Brainard GC, Blask DE, Lockley SW, Motta ME. Adverse Health Effects of Nighttime Lighting: Comments on American Medical Association Policy Statement. Am J Prev Med 2013;45:343-6. http://dx.doi.org/10.1016/j. amepre.2013.04.011.

Richard G Stevens, PhD, ${ }^{1}$ Yong Zhu, PhD ${ }^{2}$

1 University of Connecticut Health Center, Farmington, CT, USA

2 Environmental Health Sciences, School of Public Health, Yale University, New Haven, CT, USA

Correspondence to: Richard G Stevens, University of Connecticut Health Center, Farmington, CT, 06030-6325, USA.Email: bugs@uchc.edu] 